\title{
First Ionization Potentials of Fm, Md, No, and Lr: Verification of Filling-Up of $5 f$ Electrons and Confirmation of the Actinide Series
}

Tetsuya K. Sato, ${ }^{*}{ }^{\dagger} \odot$ Masato Asai, ${ }^{\dagger}$ Anastasia Borschevsky, ${ }^{\ddagger}$ Randolf Beerwerth, ${ }^{\S, \perp}$ Yusuke Kaneya, ${ }^{\dagger, \|}$ Hiroyuki Makii, ${ }^{\dagger}$ Akina Mitsukai, ${ }^{\dagger, \|}$ Yuichiro Nagame, ${ }^{\dagger, \|}$ Akihiko Osa, ${ }^{\dagger}$ Atsushi Toyoshima, ${ }^{\dagger}$ Kazuaki Tsukada, ${ }^{\dagger}$ Minoru Sakama, ${ }^{\#}$ Shinsaku Takeda, ${ }^{\#}$ Kazuhiro Ooe, ${ }^{\nabla}$ Daisuke Sato, ${ }^{\nabla}$ Yudai Shigekawa, ${ }^{\otimes}$ Shin-ichi Ichikawa, ${ }^{\bullet}$ Christoph E. Düllmann, ${ }^{\mathbb{T}, \boldsymbol{\Lambda}, \times}$ Jessica Grund, ${ }^{\mathrm{d}}, \boldsymbol{,}$ Dennis Renisch, ${ }^{\text {T, }} \boldsymbol{\Delta}$ Jens V. Kratz, ${ }^{\text {II }}$ Matthias Schädel, ${ }^{\times}$Ephraim Eliav, ${ }^{\square}$ Uzi Kaldor, ${ }^{\square}$ Stephan Fritzsche, ${ }^{\S, \perp}$ and Thierry Stora

$\dagger$ Japan Atomic Energy Agency (JAEA), Tokai, Ibaraki 319-1195, Japan

ॠThe Van Swinderen Institute for Particle Physics and Gravity, University of Groningen, 9700 AB Groningen, The Netherlands

${ }^{\S}$ Theoretisch-Physikalisches Institut, Friedrich-Schiller-Universität, 07743 Jena, Germany

${ }^{\perp}$ Helmholtz-Institut Jena, 07743 Jena, Germany

"Graduate School of Science and Engineering, Ibaraki University, Mito, Ibaraki 310-8512, Japan

${ }^{\#}$ Graduate School of Biomedical Sciences, Tokushima University, Tokushima 770-8503, Japan

${ }^{\nabla}$ Graduate School of Science and Technology, Niigata University, Niigata 910-2181, Japan

${ }^{\otimes}$ Graduate School of Science, Osaka University, Toyonaka, Osaka 560-0043, Japan

-Nishina Center for Accelerator-Based Science, RIKEN, Wako, Saitama 351-0198, Japan

IIInstitut für Kernchemie, Johannes Gutenberg-Universität Mainz, 55099 Mainz, Germany

$\boldsymbol{\Delta}_{\text {Helmholtz-Institut Mainz, } 55099 \text { Mainz, Germany }}$

${ }^{\times}$GSI Helmholtzzentrum für Schwerionenforschung, 64291 Darmstadt, Germany

$\square_{\text {School of Chemistry, Tel Aviv University, } 69978 \text { Tel Aviv, Israel }}$

${ }^{\circ}$ ISOLDE, CERN, 1211 Geneva, Switzerland

Supporting Information

ABSTRACT: We report the first ionization potentials $\left(\mathrm{IP}_{1}\right)$ of the heavy actinides, fermium (Fm, atomic number $Z=100)$, mendelevium ( $M d, Z=101)$, nobelium (No, $Z=102$ ), and lawrencium ( $\mathrm{Lr}, Z=103$ ), determined using a method based on a surface ionization process coupled to an online mass separation technique in an atom-at-a-time regime. The measured $\mathrm{IP}_{1}$ values agree well with those predicted by state-of-the-art relativistic calculations performed alongside the present measurements. Similar to the well-established behavior for the lanthanides, the $\mathrm{IP}_{1}$ values of the heavy actinides up to No increase with filling up the $5 \mathrm{f}$ orbital, while that of $\mathrm{Lr}$ is the lowest among the actinides. These results clearly demonstrate that the $5 f$ orbital is fully filled at No with the $[\mathrm{Rn}] 5 \mathrm{f}^{14} 7 \mathrm{~s}^{2}$ configuration and that $\mathrm{Lr}$ has a weakly bound electron outside the No core. In analogy to the lanthanide series, the present results unequivocally verify that the actinide series ends with Lr.

巨. xtending the periodic table and classifying newly discovered heavy elements are among the most fundamental and exciting aspects of the chemical sciences. This leads to architect the periodic table and revise its structure in the heavy element region. The most recent revision of the structure of the periodic table took place in the 1940s when Glenn T. Seaborg introduced the ground-breaking actinide concept, ${ }^{1,2}$ placing a new actinide series below the lanthanides. In this new series, the $5 \mathrm{f}$ electron shell is filled in a manner similar to the filling of the $4 \mathrm{f}$ electron shell in lanthanides. The actinide concept did not only allow for the immediate discoveries of the elements 95, americium, and 96, curium, but was also instrumental for the discovery of heavier ones. Chemical properties of weighable amounts of nuclear-reactorproduced actinides up to Fm have been extensively studied. ${ }^{3}$ However, much less is known about the heavier actinides due to stringent limitation on experimental procedures ${ }^{4}$ with increasing atomic number as these heavy elements are available in decreasing quantities of only one atom at a time. ${ }^{5,6}$

The first ionization potential $\left(\mathrm{IP}_{1}\right)$ of an atom is one of the most fundamental chemical and physical quantities of every element. The first measurements of $\mathrm{IP}_{1}$ of actinides were performed by a surface ionization technique. ${ }^{7}$ Then laser spectroscopy and resonance ionization mass spectroscopy of macroscopically available actinides up to einsteinium have been conducted to measure accurate $\mathrm{IP}_{1}$ values. $^{8-11}$

Received: September 7, 2018

Published: October 25, 2018 
Table 1. $\mathrm{IP}_{1} *$ Obtained from $I_{\text {eff }}$ and $N$ at Temperature $T$

\begin{tabular}{|c|c|c|c|c|c|c|}
\hline element & $T(\mathrm{~K})$ & $I_{\text {eff }}(\%)$ & $N$ & $\mathrm{IP}_{1} *(\mathrm{eV})$ & $k T \ln \left(Q_{\mathrm{i}} / Q_{0}\right)(\mathrm{eV})$ & $\mathrm{IP}_{1}^{a}(\mathrm{eV})$ \\
\hline${ }^{100} \mathrm{Fm}$ & $2900 \pm 100$ & $1.3 \pm 0.4$ & $71 \pm 20$ & $6.39 \pm 0.13$ & $0.13 \pm 0.02$ & $6.52 \pm 0.13$ \\
\hline${ }^{101} \mathrm{Md}$ & $2900 \pm 100$ & $1.2 \pm 0.3$ & $71 \pm 20$ & $6.43 \pm 0.13$ & $0.16 \pm 0.01$ & $6.59 \pm 0.13$ \\
\hline${ }^{102} \mathrm{No}$ & $2850 \pm 803000 \pm 100$ & $0.54 \pm 0.090 .77 \pm 0.10$ & $43 \pm 834 \pm 7$ & $6.44 \pm 0.086 .45_{-0.10}^{+0.09}$ & $0.17 \pm 0.010 .18 \pm 0.01$ & $6.61 \pm 0.086 .63_{-0.10}^{+0.08}$ \\
\hline${ }_{103} \mathrm{Lr}$ & $2550 \pm 502850 \pm 50$ & $23 \pm 539 \pm 6$ & $35 \pm 347 \pm 3$ & $5.31_{-0.06}^{+0.09} 5.30_{-0.05}^{+0.09}$ & $-0.37_{-0.04}^{+0.06}-0.32_{-0.04}^{+0.06}$ & $4.99_{-0.07}^{+0.10} 4.94_{-0.07}^{+0.10}$ \\
\hline
\end{tabular}

Recently, we reported the successful measurement of $\mathrm{IP}_{1}$ of $\mathrm{Lr}$ in an atom-at-a-time scale experiment using a method based on surface ionization coupled to mass separation and $\alpha$-particle detection techniques. ${ }^{12}$ The result suggested that $\mathrm{Lr}$ has the lowest $\mathrm{IP}_{1}$ value of all actinide elements, although those of other heavy actinides, Fm, Md, and No, have not yet been determined experimentally. According to the systematic variation of the $\mathrm{IP}_{1}$ values of heavy actinides, an increasing trend is anticipated up to No due to filling electrons up in the $5 \mathrm{f}$ orbital. ${ }^{13-16}$ Nobelium is expected to have the highest $\mathrm{IP}_{1}$ among the actinides due to the closed-shell structure of $[\mathrm{Rn}] 5 \mathrm{f}^{14} 7 \mathrm{~s}^{2}$. Very recently laser resonance ionization spectroscopy of No, using ${ }^{254} \mathrm{No}$ (half-life, $T_{1 / 2}=51.2 \mathrm{~s}$ ) in one-atomat-a-time quantities, was performed and the $\mathrm{IP}_{1}$ has been measured to be $6.62621 \pm 0.00005 \mathrm{eV},{ }^{17,18}$ supporting the scenario of closed $5 \mathrm{f}$ and $7 \mathrm{~s}$ atomic shells in No. However, to unequivocally confirm the filling of the $5 \mathrm{f}$ electron shell in the heavy actinides, it is indispensable to experimentally determine the successive $\mathrm{IP}_{1}$ values from $\mathrm{Fm}$ to $\mathrm{Lr}$.

In the present study, we have applied the earlier developed surface-ionization method ${ }^{12}$ to determine the $\mathrm{IP}_{1}$ values of $\mathrm{Fm}$, $\mathrm{Md}$, and No. In addition, $\mathrm{IP}_{1}$ of $\mathrm{Lr}$ has been also measured to improve the accuracy of the previously reported $\mathrm{IP}_{1} \cdot{ }^{12}$ Surface

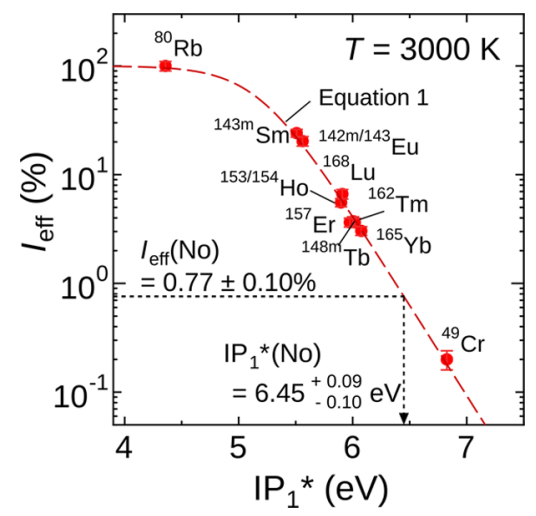

Figure 1. Ionization efficiency $\left(I_{\text {eff }}\right)$ of various short-lived isotopes as a function of the effective $\mathrm{IP}_{1}, \mathrm{IP}_{1}{ }^{*}$, at $3000 \mathrm{~K}$. The red-dashed curve is obtained by fitting eq 1 to the experimental data.

ionization process takes place on a solid surface kept at a high temperature and can be described by the Saha-Langmuir ( $\mathrm{S}$ L) equation. ${ }^{19}$ The ionization efficiency $\left(I_{\text {eff }}\right)$ depends on the work function of the ionizing material, $\phi(\mathrm{eV})$, the temperature of the material surface, $T(\mathrm{~K})$, and $\mathrm{IP}_{1}$ of the element. The detailed experimental setup and the analytical method used in this work have been described in our previous papers. ${ }^{12,20,21}$

Short-lived isotopes ${ }^{249} \mathrm{Fm}\left(T_{1 / 2}=2.6 \mathrm{~min}\right),{ }^{251} \mathrm{Md}\left(T_{1 / 2}=\right.$ $4.27 \mathrm{~min}),{ }^{257} \mathrm{No}\left(T_{1 / 2}=24.5 \mathrm{~s}\right)$, and ${ }^{256} \mathrm{Lr}\left(T_{1 / 2}=27 \mathrm{~s}\right)$ were produced in nuclear fusion reactions (Supplement Table 1). The produced atoms, recoiling from the target, were transported via a Teflon capillary ${ }^{20-22}$ to a surface ion-source installed at the JAEA-ISOL (Isotope Separator Online) by the $\mathrm{He} / \mathrm{CdI}_{2}$ gas-jet transport system. ${ }^{21}$ Transported products were injected into the ionization cavity of the ion-source. Metallic tantalum ( $\mathrm{Ta}$ ) was selected as the cavity material in this work. The products were surface-ionized on the hot surface of the Ta cavity kept at a temperature between 2550 and $3000 \mathrm{~K}$. Produced ions are extracted and mass separated in the ISOL. The number of collected ions after the massseparation was determined by $\alpha$ spectrometry. ${ }^{12,20}$ The $I_{\text {eff }}$ value was calculated from a ratio of the number of massseparated ions to that of directly collected atoms transported by the gas-jet system. ${ }^{20}$

The $\alpha$ spectra after surface ionization and following massseparation are shown in Supplement Figures 1-4. The measured $I_{\text {eff }}$ values for ${ }^{249} \mathrm{Fm},{ }^{251} \mathrm{Md},{ }^{257} \mathrm{No}$, and ${ }^{256} \mathrm{Lr}$ are listed in Table 1 with the related surface temperature. On the basis of the S-L equation, ${ }^{19,23} I_{\text {eff }}$ in a small cavity configuration can be expressed as ${ }^{12,24}$

$$
I_{\text {eff }}=\frac{N \exp \left(\frac{\phi-\mathrm{IP}_{1}^{*}}{k T}\right)}{1+N \exp \left(\frac{\phi-\mathrm{IP}_{1}^{*}}{k T}\right)},
$$

where $N$ is a parameter that depends on the effective number of atom-surface interactions in the cavity, and $k$ is the Boltzmann constant. $\mathrm{IP}_{1}{ }^{*}$, the effective $\mathrm{IP}_{1}$, is directly related to the $\mathrm{IP}_{1}$ as ${ }^{19,23}$

$$
\mathrm{IP}_{1}^{*}=\mathrm{IP}_{1}-k T \ln \left(\frac{Q_{i}}{Q_{0}}\right)
$$

where $Q_{i}$ and $Q_{0}$ are the partition functions for the ion and atoms at a given temperature, which can be calculated using excitation energies and statistical weights of their ground and excited states. Thus, $\mathrm{IP}_{1}{ }^{*}$ can be calculated from the experimentally determined $I_{\text {eff }}$ value of the isotope of interest via eq 1 . Then, $\mathrm{IP}_{1} *$ can be converted to $\mathrm{IP}_{1}$ using eq 2 .

To confirm the correlation between $I_{\text {eff }}$ and $\mathrm{IP}_{1} *$ in the present system, $I_{\text {eff }}$ values of short-lived lanthanides, an alkali metal, and a chromium isotope were measured. The short-lived isotopes, ${ }^{143 \mathrm{~m}} \mathrm{Sm},{ }^{142 \mathrm{~m}, 143} \mathrm{Eu},{ }^{148 \mathrm{~m}} \mathrm{~Tb},{ }^{153,154} \mathrm{Ho},{ }^{157} \mathrm{Er},{ }^{162} \mathrm{Tm}$, ${ }^{165} \mathrm{Yb},{ }^{168} \mathrm{Lu},{ }^{80} \mathrm{Rb}$, and ${ }^{49} \mathrm{Cr}$ were employed. Figure 1 shows the typical plot of the measured $I_{\text {eff }}$ values vs $\mathrm{IP}_{1} *$ of these elements at $T=3000 \mathrm{~K}$. The $\mathrm{IP}_{1} *$ values of the above elements were calculated via eq 2 using their known $\mathrm{IP}_{1}$ values compiled in the National Institute of Standard and Technology (NIST) atomic spectra database (ASD) ${ }^{25}$ Low-lying excited states for the calculation of $Q_{i}$ and $Q_{0}$ were also taken from NIST ASD. Values of the parameter $N$ were obtained by a best-fit with eq 1 to the measured $I_{\text {eff }}$ values for the isotopes; summarized with the other quantities in Table 1 . The determination of $\mathrm{IP}_{1}{ }^{*}=$ $6.45 \mathrm{eV}$ for No from $I_{\text {eff }}=0.77 \%$ at $T=3000 \mathrm{~K}$ is depicted in Figure 1. The $I_{\text {eff }}$ vs $\mathrm{IP}_{1} *$ plot at $2900 \mathrm{~K}$ for $\mathrm{Md}$ and $\mathrm{Fm}$ is shown in Supplement Figure 5. 
Table 2. Experimental and Theoretical IP 1 Values

\begin{tabular}{|c|c|c|c|c|c|}
\hline \multirow[b]{2}{*}{ ref } & \multirow[b]{2}{*}{ method } & \multicolumn{4}{|c|}{$\mathrm{IP}_{1}(\mathrm{eV})$} \\
\hline & & $\mathrm{Fm}$ & $\mathrm{Md}$ & No & $\mathrm{Lr}$ \\
\hline \multicolumn{6}{|c|}{ Theoretical } \\
\hline Sugar $^{13}$ & semiempirical & 6.50 & 6.58 & 6.65 & \\
\hline Rajnak and Shore ${ }^{14}$ & semiempirical & 6.46 & 6.57 & 6.67 & \\
\hline Liu et al. ${ }^{15}$ & QRPP-CASSCF+APCF ${ }^{a}$ & 6.26 & 6.10 & 6.14 & 5.28 \\
\hline Cao et al. ${ }^{31}$ & $\mathrm{RPP}-\mathrm{CASSCF}+\mathrm{APCF}^{b}$ & 6.13 & 6.23 & 6.27 & 4.79 \\
\hline \multirow[t]{2}{*}{ Borschevsky et al. ${ }^{12,28}$} & \multirow[t]{2}{*}{ IHFSCC } & & & 6.632 & $4.963(15)$ \\
\hline & & & & ref 28 & ref $12^{d}$ \\
\hline Pantazis and Neese ${ }^{16}$ & $\mathrm{DKH}^{2-B 3 L_{Y P}}{ }^{c}$ & 6.45 & 6.54 & 6.64 & 4.56 \\
\hline Dzuba et al. ${ }^{32}$ & $\mathrm{CI}+\mathrm{SD}^{d}$ & & & 6.743 & 4.9 \\
\hline \multirow[t]{2}{*}{ present work } & $\operatorname{CCSD}(\mathrm{T})$ & 6.469 & 6.557 & 6.638 & \\
\hline & MCDF & 6.22 & & & \\
\hline \multicolumn{6}{|c|}{ Experimental } \\
\hline \multirow[t]{2}{*}{ literature } & & $<6.76$ & & $6.62621(5)$ & $4.96_{-0.07}^{+0.08}$ \\
\hline & & ref 33 & & ref 18 & ref 12 \\
\hline present work & & $6.52 \pm 0.13$ & $6.59 \pm 0.13$ & $6.62_{-0.07}^{+0.06}$ & $4.96_{-0.04}^{+0.05}$ \\
\hline
\end{tabular}

${ }^{a}$ Quasirelativistic ab initio pseudopotential (QRPP) complete active space self-consistent field (CASSCF) calculations combined with averaged coupled-pair functional (ACPF) and corrected for spin-orbit coupling. ${ }^{b}$ Relativistic ab initio pseudopotential (RPP) CASSCF calculations combined with ACPF and corrected for spin-orbit coupling. ${ }^{c}$ Second order Douglas-Kroll-Hess approach combined with density functional theory (B3LYP functional). ${ }^{d}$ Relativistic configuration interaction (CI) combined with the linearized single-double coupled cluster method.

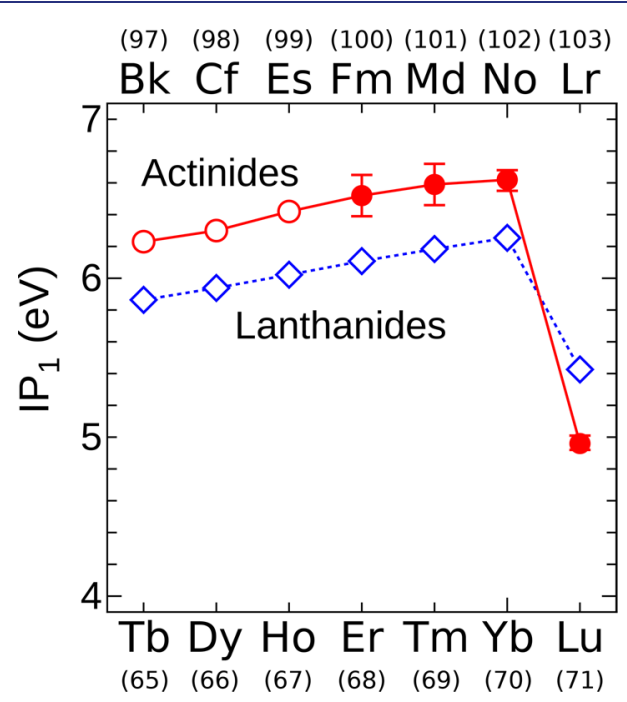

Figure 2. Variation of the experimental $\mathrm{IP}_{1}$ values of heavy actinides and heavy lanthanides with atomic numbers. Closed circles indicate the values obtained in the present work.

To calculate the $\mathrm{IP}_{1}$ values of $\mathrm{Fm}, \mathrm{Md}$, No, and $\mathrm{Lr}$ from their $\mathrm{IP}_{1}$ * values, excitation energies and statistical weights of the low-lying states of each atom and ion are required. As no experimental data on excited states in the heavy actinides are available, we calculated these values using relativistic computational methods. The intermediate-Hamiltonian Fock space coupled cluster (IHFSCC) method ${ }^{26}$ was applied to calculations of the atomic and ionic states of $\mathrm{Md}$ and No (for some of the levels the single reference coupled cluster with single, double, and perturbative triple excitations $(\operatorname{CCSD}(\mathrm{T}))$ was employed), while the Multi-Configuration Dirac-Fock (MCDF) method, as implemented in the Graps $2 \mathrm{k}$ code, ${ }^{27}$ was used for the Fm atom and its ion. Excited states of No and Lr were taken from refs 28,29 , where they were also calculated within the IHFSCC approach. The methods used here were also applied to the lower excitation energies of the lanthanide homologues of the elements of interest ( $\mathrm{Er}, \mathrm{Tm}, \mathrm{Yb}$, and $\mathrm{Lu}$ ). For the lighter elements, we can compare our results to the available experimental data, thus assessing the accuracy of our calculations and of our predictions for Fm through Lr. The obtained values are compiled in the Supplement Table 2. Although several low-lying states were found in $\mathrm{Fm}^{+}$, only one state should be considered for the Fm atom (Supporting Information). There are no excited states in the range of interest for $\mathrm{Md}$, while one state is present for $\mathrm{Md}^{+}$. In No and $\mathrm{No}^{+}$, only the ground states are expected to contribute. The errors in the energy of the excited states were evaluated from relative errors of the calculated values compared to the experimental transition energies of the respective lanthanide homologues. The $k T \ln \left(Q_{j} / Q_{0}\right)$ values are presented in Table 1. For the case of $\mathrm{Lr}$, the values were obtained in the same manner in ref 12 . The $\mathrm{IP}_{1}$ values of $\mathrm{Fm}, \mathrm{Md}$, and No are determined to be $6.52 \pm 0.13,6.59 \pm 0.13$, and $6.62_{-0.07}^{+0.06} \mathrm{eV}$, respectively, where $\mathrm{IP}_{1}$ of No was obtained by taking a weighted average of the $\mathrm{IP}_{1}$ values listed in Table 1 . A more accurate $\mathrm{IP}_{1}$ of $\mathrm{Lr}$ of $4.96_{-0.04}^{+0.05} \mathrm{eV}$ was determined by also taking a weighted average of our previous ${ }^{12}$ and present values. Errors in $\mathrm{IP}_{1}$ mainly come from counting statistics, surface temperature, and fitting procedure with eq 1 .

In parallel to the measurements, we calculated the $\mathrm{IP}_{1}$ values of Fm, Md, and No within the relativistic $\operatorname{CCSD}(\mathrm{T})$ approach, corrected for the Breit term and the higher order quantum electrodynamic (QED) corrections, using a similar scheme to that employed in ref 30.

The experimental and theoretical $\mathrm{IP}_{1}$ values obtained in the present work are summarized in Table 2 together with earlier theoretical predictions ${ }^{12-16,28,31,32}$ and measurements. ${ }^{12,18,33}$ The present experimental values for $\mathrm{Md}$ and No agree with the semiempirical values ${ }^{13,14}$ as well as with the more recent relativistic calculations ${ }^{28}$ for No and the DKH2-B3LYP calculations ${ }^{16}$ for both atoms. Our result on $\mathrm{IP}_{1}$ of No also agrees with the recent value from laser-spectroscopic measurements, ${ }^{18}$ thus providing independent validation to our experimental method. The calculated $\mathrm{IP}_{1}$ of $\mathrm{Er}$, the homologue 
of $\mathrm{Fm}$, is $5.94 \mathrm{eV}$ as obtained from the present MCDF calculation, that is significantly lower than the experimental value of $6.11 \mathrm{eV}$. Therefore, the MCDF prediction probably also underestimates the $\mathrm{IP}_{1}$ value of $\mathrm{Fm}$. The $\operatorname{CCSD}(\mathrm{T})+$ Breit + QED calculations of $\mathrm{IP}_{1}$ agree well with the measurements for all elements investigated here.

The variation of the $\mathrm{IP}_{1}$ values of the heavy actinides with atomic number in comparison with those of the heavy lanthanides is shown in Figure 2. As expected from the prediction, ${ }^{13-16}$ the $\mathrm{IP}_{1}$ values increase up to No via $\mathrm{Fm}$ and $\mathrm{Md}$ with filling of the $5 \mathrm{f}$ orbital in analogy to the heavy lanthanides. We take this as an indication that the $5 f$ orbital is fully filled at No. The lowest $\mathrm{IP}_{1}$ value of $\mathrm{Lr}$ is confirmed; the ground-state electronic configuration of the $\mathrm{Lr}$ atom has closed $5 \mathrm{f}^{14}$ and $7 \mathrm{~s}^{2}$ shells with an additional weakly bound electron in the valence orbital. The results unambiguously confirm that the actinide series end with $\mathrm{Lr}^{34}$

\section{ASSOCIATED CONTENT}

\section{S Supporting Information}

The Supporting Information is available free of charge on the ACS Publications website at DOI: 10.1021/jacs.8b09068.

Experimental details of the nuclear reactions for the production of the short-lived actinide isotopes, ${ }^{249} \mathrm{Fm}$, ${ }^{251} \mathrm{Md},{ }^{257} \mathrm{No}$, and ${ }^{256} \mathrm{Lr}$ and for production of various isotopes used to determine a relationship between $\mathrm{IP}_{1}$ * and $I_{\text {eff }}$ in the present system; alpha spectra of ${ }^{249} \mathrm{Fm},{ }^{251}$ $\mathrm{Md},{ }^{257} \mathrm{No}$, and ${ }^{256} \mathrm{Lr}$ measured after mass-separation; ionization efficiencies of various short-lived isotopes as a function of the $\mathrm{IP}_{1}^{*}$ at $2900 \mathrm{~K}$, which was used for $\mathrm{IP}_{1}$ calculations of $\mathrm{Md}$ and $\mathrm{Fm}$; and summary of computed low-lying level energies for the $\mathrm{Fm}, \mathrm{Md}$, and No atoms and ions together with those of respective lanthanide homologues, Er, Tm, and $\mathrm{Yb}$ (PDF)

\section{AUTHOR INFORMATION}

\section{Corresponding Author}

*sato.tetsuya@jaea.go.jp

\section{ORCID $\odot$}

Tetsuya K. Sato: 0000-0002-5490-9178

\section{Notes}

The authors declare no competing financial interest.

\section{ACKNOWLEDGMENTS}

The authors would like to thank the JAEA tandem accelerator crew for supplying intense and stable beams for the experiments. The ${ }^{249} \mathrm{Cf}$ was produced in the form of ${ }^{249} \mathrm{Bk}$ through the former Transplutonium Element Production Program at Oak Ridge National Laboratory (ORNL) under the auspices of the Director, Office of Science, Office of Basic Energy Sciences, Chemical Sciences, Geosciences, and Biosciences Division of US Department of Energy. It was made available by $\mathrm{H}$. Nitsche of University of California, Berkeley, USA, and we acknowledge the LBNL Nuclear Science Division's R. F. Fairchild II, N. E. Reeves, J. A. Van Wart, and the Radiation Protection Group of the Environmental Health and Safety Division for their support with the preparation and execution of the ${ }^{249} \mathrm{Cf}$ shipment to Germany. Financial support by the Helmholtz-Institut Mainz is gratefully acknowledged. This work has been partly supported by the Grant-in-Aid for Scientific Research (A) No. 16H02130, (B)
No. 26288028, and (C) No. 26390119 of the Ministry of Education, Science, Sports and Culture (MEXT).

\section{REFERENCES}

(1) Seaborg, G. T. The Chemical and Radioactive Properties of the Heavy Elements. Chem. Eng. News 1945, 23, 2190.

(2) Seaborg, G. T. The Transuranium Elements. Science 1946, 104, 379.

(3) The Chemistry of the Actinide and Transactinide Elements, 3rd ed.; Morss, L. R., Edelstein, N. M., Fuger, J., Katz, J. J., Eds.; Springer: Dordrecht, 2006.

(4) Silva, R. In The Chemistry of the Actinide and Transactinide Elements, 3rd ed.; Morss, L. R.; Edelstein, N. M., Fuger, J., Katz, J. J., Eds.; Springer: Dordrecht, 2006; Vol. 3, Chapter 13, pp 1621-1651.

(5) Hoffman, D. C.; Lee, D. N. Chemistry of the Heaviest ElementsOne Atom at a Time. J. Chem. Educ. 1999, 76, 331.

(6) Türler, A.; Pershina, V. Advances in the Production and Chemistry of the Heaviest Elements. Chem. Rev. 2013, 113, 1237.

(7) (a) Hertel, G. R. Surface Ionization. II. The First Ionization Potential of Uranium. J. Chem. Phys. 1967, 47, 335. (b) Smith, D. H.; Hertel, G. R. First Ionization Potentials of Th, Np, and Pu by Surface Ionization. J. Chem. Phys. 1969, 51, 3105.

(8) Worden, E. F.; Blaise, J.; Fred, M.; Trautmann, N.; Wyart, J.-F. In The Chemistry of the Actinide and Transactinide Elements, 3rd ed.; Morss, L. R., Edelstein, N. M., Fuger, J., Katz, J. J., Eds.; Springer: Dordrecht, 2006; Vol. 3, Chapter 16, pp 1836-1892.

(9) Köhler, S.; Deißenberger, R.; Eberhardt, K.; Erdmann, N.; Herrmann, G.; Huber, G.; Kratz, J. V.; Nunnemann, M.; Passler, G.; Rao, P. M.; Riegel, J.; Trautmann, N.; Wendt, K. Determination of the first ionization potential of actinide elements by resonance ionization mass spectroscopy. Spectrochim. Acta, Part B 1997, 52, 717.

(10) Peterson, J. R.; Erdmann, N.; Nunnemann, M.; Eberhardt, K.; Huber, G.; Kratz, J. V.; Passler, G.; Stetzer, O.; Thörle, P.; Trautmann, N.; Waldek, A. Determination of the first ionization potential of einsteinium by resonance ionization mass spectroscopy (RIMS). J. Alloys Compd. 1998, 271-273, 876.

(11) Wendt, K.; Gottwald, T.; Mattolat, C.; Raeder, S. Ionization potentials of the lanthanides and actinides - towards atomic spectroscopy of super-heavy elements. Hyperfine Interact. 2014, 227, 55.

(12) Sato, T. K.; Asai, M.; Borschevsky, A.; Stora, T.; Sato, N.; Kaneya, Y.; Tsukada, K.; Düllmann, Ch. E.; Eberhardt, K.; Eliav, E.; Ichikawa, S.; Kaldor, U.; Kratz, J. V.; Miyashita, S.; Nagame, Y.; Ooe, K.; Osa, A.; Renisch, D.; Runke, J.; Schädel, M.; Thörle-Pospiech, P.; Toyoshima, A.; Trautmann, N. Measurement of the first ionization potential of lawrencium, element 103. Nature 2015, 520, 209.

(13) (a) Sugar, J. Ionization energies of the neutral actinides. J. Chem. Phys. 1973, 59, 788. (b) Sugar, J. Revised ionization energies of the neutral actinides. J. Chem. Phys. 1974, 60, 4103.

(14) Rajnak, K.; Shore, B. W. Regularities in s-electron binding enegies in $l^{\mathrm{N}} s^{\mathrm{M}}$ configurations. J. Opt. Soc. Am. 1978, 68, 360.

(15) Liu, W.; Küchle, W.; Dolg, M. Ab initio pseudopotential and density-functional all-electron study of ionization and excitation energies of actinide atoms. Phys. Rev. A: At., Mol., Opt. Phys. 1998, 58, 1103.

(16) Pantazis, D. A.; Neese, F. All-Electron Scalar Relativistic Basis Sets for the Actinides. J. Chem. Theory Comput. 2011, 7, 677.

(17) Laatiaoui, M.; Lauth, W.; Backe, H.; Block, M.; Ackermann, D.; Cheal, B.; Chhetri, P.; Düllmann, Ch. E.; Van Duppen, P.; Even, J.; Ferrer, R.; Giacoppo, F.; Götz, S.; Heßberger, F. P.; Huyse, M.; Kaleja, O.; Khuyagbaatar, J.; Kunz, P.; Lautenschläger, F.; Mistry, A. K.; Raeder, S.; Ramirez, E. M.; Walther, T.; Wraith, C.; Yakushev, A. Atom-at-a-time laser resonance ionization spectroscopy of nobelium. Nature 2016, 538, 495.

(18) Chhetri, P.; Ackermann, D.; Backe, H.; Block, M.; Cheal, B.; Droese, C.; Düllmann, Ch. E.; Even, J.; Ferrer, R.; Giacoppo, F.; Götz, S.; Heßberger, F. P.; Huyse, M.; Kaleja, O.; Khuyagbaatar, J.; Kunz, P.; Laatiaoui, M.; Lautenschläger, F.; Lauth, W.; Lecesne, N.; Lens, L.; Minaya Ramirez, E.; Mistry, A. K.; Raeder, S.; Van Duppen, P.; 
Walther, Th.; Yakushev, A.; Zhang, Z. Precision Measurement of the First Ionization Potential of Nobelium. Phys. Rev. Lett. 2018, 120, 263003.

(19) Zandberg, É. Ya.; Ionov, N. I. Surface ionization. Sov. Phys. Usp. 1959, 2, 255.

(20) Sato, T. K.; Sato, N.; Asai, M.; Tsukada, K.; Toyoshima, A.; Ooe, K.; Miyashita, S.; Schädel, M.; Kaneya, Y.; Nagame, Y.; Osa, A.; Ichikawa, S.; Stora, T.; Kratz, J. V. First successful ionization of Lr (Z $=103$ ) by a surface-ionization technique. Rev. Sci. Instrum. 2013, 84, 023304.

(21) Sato, T. K.; Asai, M.; Sato, N.; Tsukada, K.; Toyoshima, A.; Ooe, K.; Miyashita, S.; Kaneya, Y.; Osa, A.; Schadel, M.; Nagame, Y.; Ichikawa, S.; Stora, T.; Kratz, J. V. Development of a He/CdI 2 gas-jet system coupled to a surface-ionization type ion-source in JAEA-ISOL: towards determination of the first ionization potential of $\operatorname{Lr}(Z=$ 103). J. Radioanal. Nucl. Chem. 2015, 303, 1253.

(22) Ichikawa, S.; Asai, M.; Tsukada, K.; Osa, A.; Ikuta, T.; Shinohara, N.; Iimura, H.; Nagame, Y.; Hatsukawa, Y.; Nishinaka, I.; Kawade, K.; Yamamoto, H.; Shibata, M.; Kojima, Y. Mass separation of neutron-rich isotopes using a gas-jet coupled thermal ion source. Nucl. Instrum. Methods Phys. Res., Sect. A 1996, 374, 330.

(23) Stora, T. Radioactive Ion Sources, Report No. CERN-2013007, p 331; http://cds.cern.ch/record/1693046.

(24) Kirchner, R. On the thermoionization in hot cavities. Nucl. Instrum. Methods Phys. Res., Sect. A 1990, 292, 203.

(25) Kramida, A.; Ralchenko, Yu.; Reader, J., NIST ASD Team; NIST Atomic Spectra Database, version 5.5.2; National Institute of Standards and Technology: Gaithersburg, MD; https://physics.nist. gov/asd [accessed Jan 30, 2018].

(26) Eliav, E.; Vilkas, M. J.; Ishikawa, Y.; Kaldor, U. Extrapolated intermediate Hamiltonian coupled-cluster approach: Theory and pilot application to electron affinities of alkali atoms. J. Chem. Phys. 2005, $122,224113$.

(27) Jönsson, P.; Bieron, J.; Fischer, C. F.; Grant, I.; Gaigalas, G. Newversion: Grasp2K Relativistic atomics structure package. Comput. Phys. Commun. 2013, 184, 2197.

(28) Borschevsky, A.; Eliav, E.; Vilkas, M. J.; Ishikawa, Y.; Kaldor, U. Predicted spectrum of atomic nobelium. Phys. Rev. A: At., Mol., Opt. Phys. 2007, 75, 042514.

(29) Borschevsky, A.; Eliav, E.; Vilkas, M. J.; Ishikawa, Y.; Kaldor, U. Transition energies of atomic lawrencium. Eur. Phys. J. D 2007, 45, 115.

(30) Borschevsky, A.; Paŝteka, L. F.; Pershina, V.; Eliav, E.; Kaldor, $\mathrm{U}$. Ionization potentials and electron affinities of the superheavy elements 115-117 and their sixth-row homologues $\mathrm{Bi}$, Po, and At. Phys. Rev. A: At., Mol., Opt. Phys. 2015, 91, 020501.

(31) Cao, X.; Dolg, M.; Stoll, H. Valence basis sets for relativistic energy-consistent small-core actinide pseudopotentials. J. Chem. Phys. 2003, 118, 487.

(32) Dzuba, V. A.; Safronova, M. S.; Safronova, U. I. Atomic properties of superheavy elements No, Lr, and Rf. Phys. Rev. A: At., Mol., Opt. Phys. 2014, 90, 012504.

(33) Sewtz, M.; Backe, H.; Dretzke, A.; Kube, G.; Lauth, W.; Schwamb, P.; Eberhardt, K.; Gruning, C.; Thorle, P.; Trautmann, N.; Lassen, J.; Passler, G.; Dong, C. Z.; Fritzsche, S.; Kunz, P.; Haire, R. G. First Observation of Atomic Levels for the Element Fermium ( $\mathrm{Z}=$ 100). Phys. Rev. Lett. 2003, 90, 163002.

(34) A debate has emerged over the places of the last lanthanide Lu and the last actinide Lr in the periodic table: Jensen, W. B. The positions of lanthanum (actinium) and lutetium (lawrencium) in the periodic table: an update. Found. Chem. 2015, 17, 23. An IUPAC task group has been formed to make a recommendation regarding the membership of group 3 of the periodic table, Project No. 2015-039-2200: Scerri, E. Which Elements Belong to Group 3 of the Periodic Table. Chem. Int. 2016, 38, 22. 